\section{Refractory Relapsing Polychondritis Treated with Serial Success with Interleukin 6 Receptor Blockade}

\section{To the Editor:}

Relapsing polychondritis (RPC) can affect the ears, eyes, larynx, trachea, bronchi, joints, audiovestibular system, and heart valves ${ }^{1,2,3}$. Therapy is difficult in the subset of patients refractory to glucocorticoids and conventional immunosuppressive agents. We describe a 65-year-old woman with RPC refractory to glucocorticoids, cyclophosphamide, and infliximab. Interleukin 6 (IL-6) inhibition led to prompt control of RPC affecting her ears, nose, and trachea, as well as swift normalization of her acute-phase reactants. Re-treatment with tocilizumab on 2 occasions following disease flares again led to prompt disease control without the use of other medications.

The patient presented with 4 months of intermittent but progressive swelling, erythema, and pain of her right ear (Figure 1A). The nasal bridge was swollen and faintly erythematous (Figure 1B), and the trachea was tender. Her left ear appeared normal (Figure 1C). She had thrombocytosis (platelets $767,000 / \mathrm{mm}^{3}$, normal $150,000-400,000 / \mathrm{mm}^{3}$ ) and elevations of the erythrocyte sedimentation rate (ESR; $103 \mathrm{~mm} / \mathrm{h}$, normal $<17 \mathrm{~mm} / \mathrm{h}$ ) and C-reactive protein (CRP; $170 \mathrm{mg} / \mathrm{dl}$, normal $<8 \mathrm{mg} / \mathrm{dl})$. Given her clinical presentation, a diagnosis of RPC was rendered and treatment was initiated with prednisone $40 \mathrm{mg}$ daily.

After 4 months of treatment, initially with high-dose glucocorticoids and then with the addition of cyclophosphamide $150 \mathrm{mg} / \mathrm{day}$, she was unable to taper prednisone below $20 \mathrm{mg} /$ day. Despite addition of infliximab $5 \mathrm{mg} / \mathrm{kg}$ to her regimen, the cartilage inflammation failed to improve and her acute-phase reactants rose (Figure 2). Nine months after presentation, her disease remained poorly controlled with persistent, destructive inflammation affecting the ears and nose. Over this time she developed complete collapse of both external auditory canals, bilateral cauliflower ears (Figures 1D, 1E), and a saddle-nose deformity (Figure 1F).

The serum IL- 6 concentration was elevated at $90 \mathrm{pg} / \mathrm{ml}$ (normal $<5.0$ $\mathrm{pg} / \mathrm{ml}$ ) despite her intense regimen of immunosuppressive medications. We therefore initiated IL-6 receptor (IL-6R) blockade with intravenous tocilizumab $8 \mathrm{mg} / \mathrm{kg} / \mathrm{month}$, and discontinued both infliximab and cyclophosphamide out of concern for potential adverse effects and because those medications had been ineffective. Her acute-phase reactants improved within days of her first dose of tocilizumab: the ESR was 39 $\mathrm{mm} / \mathrm{h}$ and CRP $1.4 \mathrm{mg} / \mathrm{dl}$ (Figure 2). One week after this addition of tocilizumab, her ear pain had resolved and her voice and breathing had returned to baseline.

Despite plans for 12 monthly infusions of tocilizumab at the start of this therapy, the patient chose to skip her second tocilizumab infusion because of anxiety about infusion medications. She presented several weeks later with recurrent chest pain and coughing. A computed tomography (CT) scan of the chest revealed diffuse wall thickening of the trachea extending from the thoracic inlet to the carina, as well as bronchiectasis in bilateral lower lobes, findings that had not been seen on a CT scan 1 year earlier. Her IL-6 level again was elevated at $55 \mathrm{pg} / \mathrm{ml}$. Resumption of tocilizumab therapy and consistent therapy over 2 consecutive monthly doses led to sustained disease control and ability to taper off her prednisone while maintaining disease control (Figure 2). Discontinuation of tocilizumab again after control of disease had been
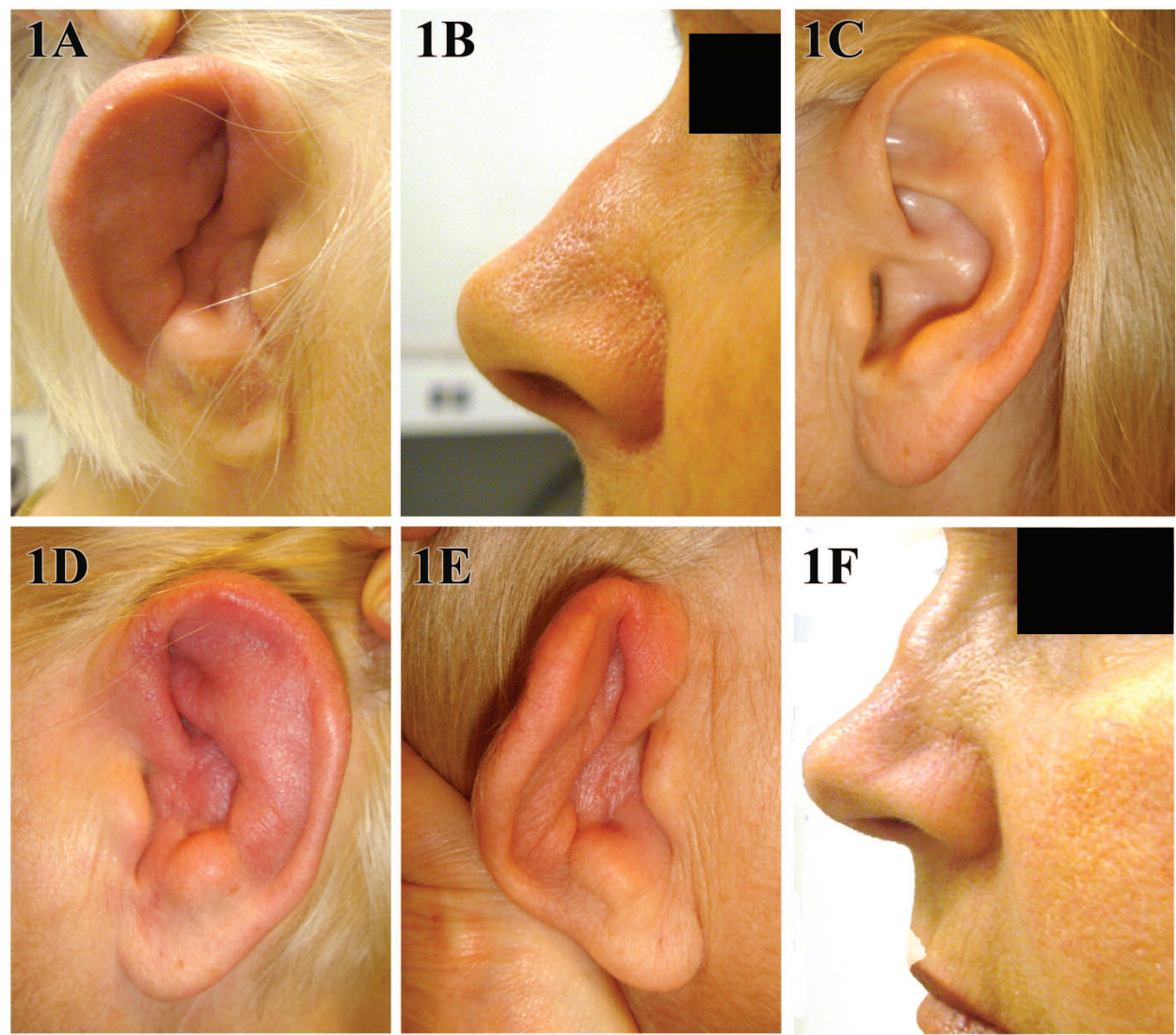

Figure 1. Clinical images of the ears and nose at presentation and followup. A. Right ear at presentation. B. Swollen and faintly erythematous nasal bridge at presentation. C. Left ear at presentation. D. Right ear at disease flare. E. Left ear following disease flare that occurred on treatment. F. Subtle saddle-nose deformity that developed during followup. 


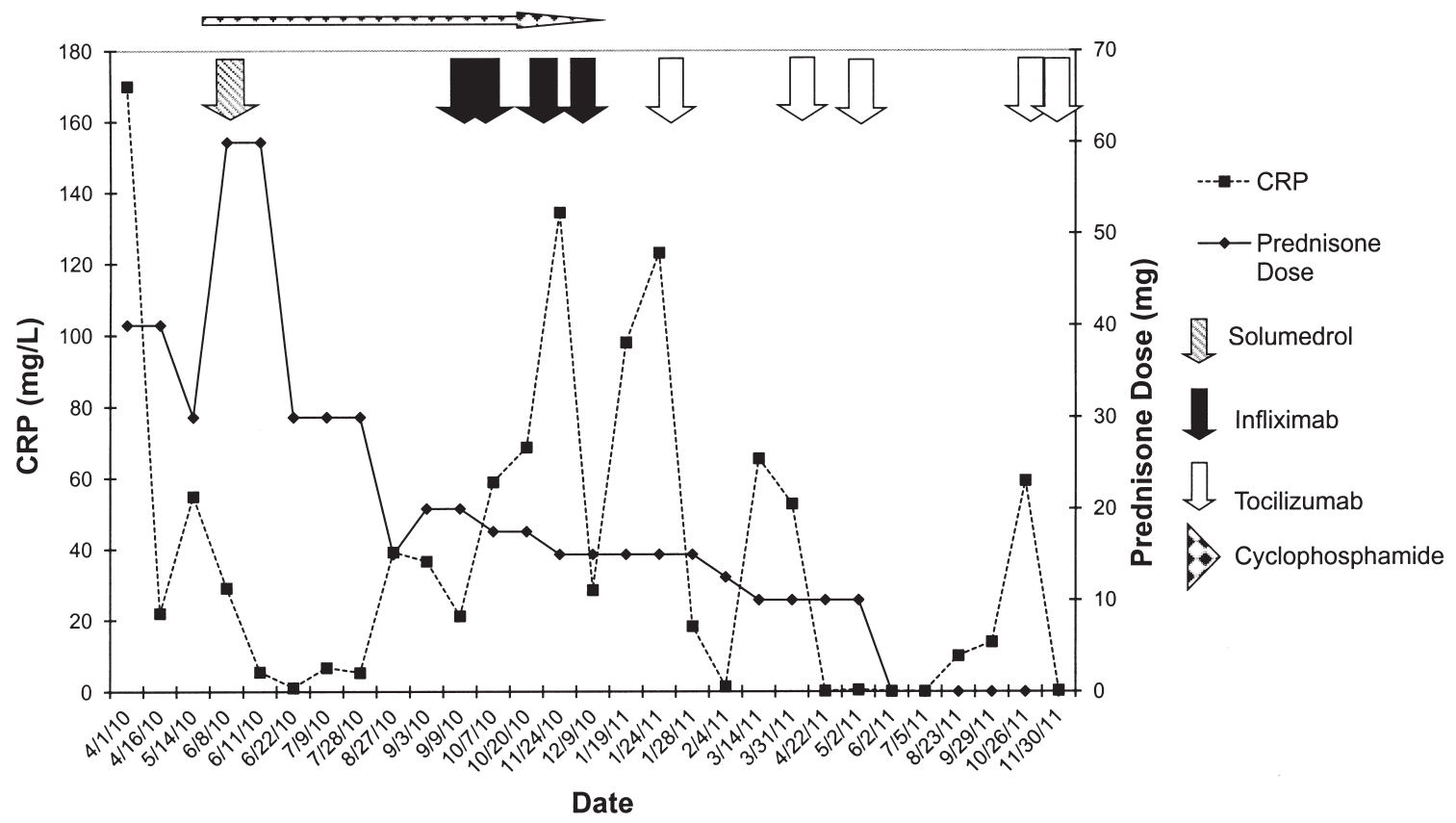

Figure 2. Timeline of the patient's medication doses and serum C-reactive protein (CRP) concentration.

reestablished led to a steep rise in both acute-phase reactants and IL-6 level $(77 \mathrm{pg} / \mathrm{ml})$ as well as the development of severe costochondritis, confirmed by positron emission tomography. These symptoms and her serological markers of inflammation resolved once again with the resumption of tocilizumab (Figure 2).

IL-6R blockade promptly suppressed not only the acute-phase response but also inflammation in the ears, nose, and tracheal cartilage, permitting discontinuation of other immunosuppressive medications. Further, cessation of tocilizumab was associated with recurrent cartilaginous inflammation and elevation of acute-phase reactant that was controlled again by the resumption of tocilizumab. Our patient tolerated tocilizumab well; she developed grade II neutropenia that was not associated with infection, a known adverse effect of tocilizumab ${ }^{4}$. She continues to do well, taking no glucocorticoid therapy, with monthly tocilizumab infusions.

IL-6 achieves its physiologic and pathologic effects through interaction with both cell-bound and soluble forms of the IL-6R (IL-6R and sIL-6R), and is a critical cytokine in the Th17 pathway of T cell development ${ }^{5,6}$. The cytokine is also a B cell stimulatory factor capable of stimulating antibody production ${ }^{5,6}$. IL-6 inhibition may therefore disrupt both cellular and humoral pathways contributing to RPC. The possible therapeutic role for IL-6R blockade in our patient was suggested by the finding of a strikingly elevated serum IL-6 concentration, although Nishimoto, et al have suggested that such a finding is not a prerequisite for efficacy with tocilizumab $^{6}$. The utility of longitudinal measurements following institution of IL-6R blockade is unclear ${ }^{6}$. IL-6R blockade leads to elevations in serum IL- 6 concentration because of the interruption of receptor-mediated metabolism.

These results support the potential usefulness of IL-6 receptor blockade in at least a subset of patients with RPC, a possibility first suggested in 2008 but not examined in any subsequent reports ${ }^{7}$. The clue to tocilizumab's possible therapeutic efficacy was the finding of an extremely high serum IL-6 concentration despite other medications. Additional studies of IL-6R blockade in RPC may identify disease subsets that are likely to respond to this intervention.
ZACHARY S. WALLACE, MD, Resident, Department of Medicine, Massachusetts General Hospital; JOHN H. STONE, MD, MPH, Director, Clinical Rheumatology, Massachusetts General Hospital, Associate Professor of Medicine, Harvard Medical School, Boston, Massachusetts, USA. Address correspondence to Dr. J.H. Stone, Rheumatology Unit, Massachusetts General Hospital, 55 Fruit St., Yawkey 2, Boston, MA 02114, USA. E-mail: jhstone@partners.org

\section{REFERENCES}

1. Lahmer T, Treiber M, von Werder A, Foerger F, Knopf A, Heemann U, et al. Relapsing polychondritis: An autoimmune disease with many faces. Autoimmun Rev 2010;9:540-6.

2. de Barros AP, Nakamura NA, Santana T de F, Motta JQ, Bianch WA. Infliximab in relapsing polychondritis. Rev Bras Reumatol 2010;50:211-6.

3. Edrees A. Relapsing polychondritis: A description of a case and review article. Rheumatol Int 2011;31:707-13.

4. Campbell L, Chen C, Bhagat SS, Parker RA, Ostor AJ. Risk of adverse events including serious infections in rheumatoid arthritis patients treated with tocilizumab: A systematic literature review and meta-analysis of randomized controlled trials. Rheumatology 2011;50:552-62.

5. Murakami M, Nishimoto N. The value of blocking IL-6 outside of rheumatoid arthritis: Current perspective. Curr Opin Rheumatol 2011;23:273-7.

6. Nishimoto N, Terao K, Mima T, Nakahara H, Takagi N, Kakehi T. Mechanisms and pathologic significances in increase in serum interleukin-6 (IL-6) and soluble IL-6 receptor after administration of an anti-IL-6 receptor antibody, tocilizumab, in patients with rheumatoid arthritis and Castleman disease. Blood 2008;112:3959-64.

7. Kawai M, Hagihara K, Hirano T, Shima Y, Kuwahara Y, Armitisu J, et al. Sustained response to tocilizumab, anti-interleukin-6 receptor antibody, in two patients with refractory relapsing polychondritis. Rheumatology 2009;48:318-9.

J Rheumatol 2013;40:1; doi:10.3899/jrheum.120381 